\title{
A comparative study of Fentanyl and Clonidine as additives to plain Bupivacaine in caudal anaesthesia in children
}

\author{
Malarvizhi T ${ }^{1}$, Kannan $^{2}$, Rajesh $^{3}$, Poornima $^{4}$ \\ ${ }^{1}$ Dr.T. Malarvizhi, Assistant Professor, Department of Anaesthesiology, Velammal Medical College Hospital \& Research \\ Institute, Madurai, Tamil Nadu. ${ }^{2}$ Dr. Kannan, Senior Consultant, Meenakshi Mission Hospital and Research Centre, \\ Madurai, ${ }^{3}$ Dr. Rajesh, Consultant, Meenakshi Mission Hospital and Research Centre, Madurai, ${ }^{4}$ Dr. Poornima, Assistant \\ Professor, Velammal Medical College Hospital \& Research Institute, Madurai, Tamil Nadu, India.
}

Address for Correspondence: Dr. T. Malarvizhi DNB, Assistant Professor, Department of Anaesthesiology, Velammal Medical College Hospital \& Research Institute, Madurai, Tamil Nadu. E-mail: dr.malarmpt@gmail.com

\begin{abstract}
Introduction: The efficacy of clonidine or fentanyl as additives to alter the neuroendocrine stress response and emergence agitation in caudal anaesthesia in children is still not clear. Objectives: To compare the efficacy and safety of Fentanyl and Clonidine as additives to plain bupivacaine in caudal anaesthesia in children. Materials \& Methods: A prospective, open labeled randomized controlled trial was conducted in Meenakshi Mission Hospital and Research Centre, Madurai, between August 2008 to June 2010. Children undergoing various elective infra-umbilical surgical procedures were included. Children were randomly assigned to either $0.5 \%$ Bupivacaine(B), Fentanyl plus $0.5 \%$ Bupivacaine (BF) or Clonidine Plus 0.5\% Bupivacaine (BC) groups. Results: A total of 90 children, with 30 subjects in each of the three intervention groups were included. Time taken for spontaneous movement was significantly higher $(151.8 \pm 11.7)$ in BC group, as compared the other two groups. The duration of postoperative analgesia was lowest in Bupivacaine (146 \pm 91.2$)$ alone group, followed by BF (293.5 \pm 154.5$)$ and BC group (510 \pm 359.9$)$. Sedation time also has shown a similar trend. The mean pain scores from 2 hours to 24 hours were highest in bupivacaine group, followed by $\mathrm{BF}$ and BC group. The differences in the sedation scores across the three study groups from 45minutes to 24-hour postoperative period were statistically significant. Conclusions: Addition of clonidine $1 \mu \mathrm{g} / \mathrm{kg}$ to $0.5 \%$ bupivacaine prolonged the duration of postoperative analgesia after a single shot caudal injection without any significant side effects when compared to bupivacaine $0.5 \%$ alone or its combination with fentanyl $1 \mu \mathrm{g} / \mathrm{kg}$.
\end{abstract}

Key words: Caudal Anaesthesia, Fentanyl and Clonidine, Children.

\section{Introduction}

The pain pathways in infancy are underdeveloped and the threshold of stimulation and sensation of pain is low at birth and the potential impact of effects of pain on the central nervous system is also high. Consequently, inappropriate pain management can influence the child's morbidity and mortality [1]. Owing to a better understanding of the neurobiology of pain in the past three decades, it has been observed that pain managing practice that use one type of pain reliever to control one of the pain pathways are usually less effective compared to those that use a combination of analgesics that control multiple pathways [2].

Manuscript received: $5^{\text {th }}$ March 2017

Reviewed: $15^{\text {th }}$ March 2017

Author Corrected: $23^{\text {rd }}$ March 2017

Accepted for Publication: $31^{\text {st }}$ March 2017
Postoperative pain causes harmful effects like variations in hemodynamic parameters in the form of rising in blood glucose, behavioral and neuroendocrine stress response in the form of increased cortisol levels, catecholamines and growth hormone [3,4]. Such responses are observed both among adults and children alike and altering this pain control process might influence the expected outcome favorably. These responses occur not only in adults but in children as well and modulation of these may favorably influence the ultimate outcome.

Opioid drugs like morphine and ketamine have been the mainstay for treatment of moderate to severe pain but have their usual side effects like nausea, vomiting, 
constipation, respiratory depression and urinary retention [5]. However, there have been attempts of decreasing their use by addition of other analgesics or techniques targeting various parts of the pain pathway to achieve equal or better analgesia. Caudal anesthesia is the oldest and presently the most widely used epidural method in children. For infra-umbilical operations in children, the caudal block is usually the preferred method of post-operative analgesia as it produces excellent and predictable pain relief, safe and easy to perform associated with least complications $[6,7]$.

Bupivacaine is the most preferred anesthetic for caudal block owing to it being long acting and relatively safe. Adjuvants like ketamine, morphine, fentanyl, clonidine have shown to improve the quality and duration of analgesia with varying degree of success $[8,9]$.

Clonidine is a common adjuvant [8, 10] with insignificant respiratory depression, bradycardia, though, its right dose with bupivacaine is still debatable. Also, some studies claim that addition of clonidine with bupivacaine in the caudal block has no additional advantage as compared to bupivacaine alone [11].

Some studies reported a satisfactory postoperative analgesia of fentanyl with bupivacaine [12] without much influence on the cardio-respiratory system. However, the efficacy of clonidine or fentanyl to alter the neuroendocrine stress response and emergence agitation is still not clear. Hence the present study assessed the combined effect of clonidine and fentanyl with bupivacaine in prolonging post-operative analgesia after caudal block in children.

\section{Objectives}

To compare the efficacy and safety of Fentanyl and Clonidine as additives to plain bupivacaine in caudal anaesthesia in children

\section{Materials and Methods}

Study design: The current study is a prospective, open labeled randomized controlled trial

Study setting: The study was conducted in Meenakshi Mission Hospital and Research Centre, Madurai, Tamil Nadu

Study duration: The study was conducted between August 2008 to June2010.
Study population: The study population included, children undergoing various elective infra-umbilical surgical procedures in the study setting. The study population was randomly assigned to three of the intervention groups

Group B: Who have been administered with $0.5 \%$ Bupivacaine

Group BF: Administered with Fentanyl, in addition to $0.5 \%$ Bupivacaine

Group BC: Administered with Clonidine in addition to $0.5 \%$ Bupivacaine.

\section{Inclusion criteria}

1. aged 10 months to 10 years

2. ASA physical status 1 and 2,

3. Elective infra-umbilical surgeries

\section{Exclusion criteria}

1. Emergency surgical procedures

2. Not willing to provide consent

Sample size: Considering the minimum difference in duration of sensory block to be detected as 30 minutes, with a standard deviation of 25 minutes with $90 \%$ power of study and 5\% alpha error, to assess two pairwise comparisons using ANOVA, the required sample size would be about 15 subjects in each group. To account for a loss to follow up of $10 \%$, it was decided to include, not less than 17 subjects I each of the study groups. Sample size was calculated using STATA IC software version 13.

Randomization: The study subjects were randomly assigned to three of the intervention groups using computer-generated random number sequence, after reassigning, a set of numbers to each intervention

Blinding: Considering the nature of the intervention, the anesthetist blinding was not possible. Participants and the statistician analyzing the data were blinded to the intervention.

Allocation concealment: The allocation sequence was kept in sealed opaque envelopes in the custody of an independent statistician and was opened after the recruitment of each subject and the intervention was administered accordingly. 
Ethical issues: The study was approved by the institutional human ethics committee. Informed written consent was obtained from the parents or guardian of all the children, after explaining the risks and benefits of the intervention. The confidentiality of the study participants was maintained.

Statistical analysis: All the three study groups were

\section{Results}

A total of 90 children, with 30 subjects in each of the three intervention groups were used. There is no statistically significant difference in the age composition of the children in three groups. There is no statistically significant difference in the sex composition of the children in three groups. The weights of the children in the three groups are similar. Duration of surgery in three groups was comparable (Table 1).

Table-1: Age and gender distribution of the study participants.

\begin{tabular}{|c|c|c|c|c|}
\hline Parameters & Group B & Group BF & Group BC & P value \\
\hline Age (Mean \pm SD) & $3.13 \pm 1.74$ & $3.27 \pm 2.24$ & $3.23 \pm 2.08$ & 0.9683 \\
\hline Male : Female Ratio & $\mathbf{3 0 : 0}$ & $\mathbf{2 9 : 1}$ & $\mathbf{2 8 : 2}$ & \\
\hline Weight & $13.37 \pm 2.72$ & $14.0 \pm 3.22$ & $13.73 \pm 2.83$ & 0.7502 \\
\hline Duration of surgery & $51.5 \pm 14.4$ & $53.3 \pm 11.5$ & $53 \pm 14.1$ & 0.6227 \\
\hline
\end{tabular}

The time taken for the spontaneous movement was significantly higher at $151.8 \pm 11.7$ in BC groups, as compared the other two groups. The duration of postoperative analgesia was lowest in Bupivacaine (146 \pm 91.2$)$ alone group, followed by BF $(293.5 \pm 154.5)$. It was longest in BC group $(510 \pm 359.9)$. Sedation time also has shown a similar trend with the shortest duration in Bupivacaine alone group, followed by BF group and longest in BC group. The differences between the three groups in all these parameters were statistically significant. (Table 2)

Table-2: Comparison of analgesic efficacy among the three groups.

\begin{tabular}{|c|c|c|c|c|}
\hline \multirow{2}{*}{ Parameter } & Group B & Group BF & Group BC & \multirow{2}{*}{ P value } \\
\cline { 2 - 4 } Time taken for spontaneous movement & Mean \pm SD & Mean \pm SD & Mean \pm SD & \multirow{2}{*}{$\mathbf{0 . 0 0 7}$} \\
\hline Post-operative Analgesia (in minutes) & $149.2 \pm 14.6$ & $149.2 \pm 14.6$ & $510 \pm 359.9$ & $<\mathbf{0 . 0 0 1}$ \\
\hline Sedation time (in minutes) & $237.5 \pm 104.9$ & $500.7 \pm 272.7$ & $624 \pm 254.9$ & $\mathbf{0 . 0 0 0 1}$ \\
\hline
\end{tabular}

No statistically significant differences were found in the mean postoperative pain scores, a cross the three study groups in the initial 60-minute post-operative period. The mean pain scores from 2 hours to 24 hours were highest in bupivacaine alone group, followed by BF groups and were least in BC group. The differences in the mean pain scores across the three groups from 2 to 24 -hour post-operative period were statistically significant with $\mathrm{P}$ values $<0.05$. (Table 3 )

There was no statistically significant difference in the sedation scores, between the two study groups in the initial 30minute post-operative period. From 45-minute post-operative period to 24-hour post-operative period, the sedation score was lowest in bupivacaine alone group, followed by BF group and highest in BC group. The differences in the sedation scores across the three study groups from 45 minutes to 24-hour post-operative period were statistically significant. (Table 4). 
Table-3: Comparison of postoperative pain scores across the three study groups.

\begin{tabular}{|c|c|c|c|c|}
\hline $\begin{array}{c}\text { Post-operative } \\
\text { Pain Score at }\end{array}$ & Group B & Group BF & Group BC & \multirow{2}{*}{ P value } \\
\cline { 2 - 4 } & Mean \pm SD & Mean \pm SD & Mean \pm SD & 0.3921 \\
\hline 15 minutes & $1.72 \pm 1.51$ & $1.67 \pm 1.37$ & $1.33 \pm 1.15$ & 0.0997 \\
\hline 30 minutes & $2.2 \pm 1.35$ & $2.37 \pm 0.93$ & $2.1 \pm 0.55$ & 0.113 \\
\hline 45 minutes & $1.93 \pm 1.6$ & $1.8 \pm 1.32$ & $1.4 \pm 0.97$ & 0.1156 \\
\hline 60 minutes & $1.77 \pm 1.69$ & $1.53 \pm 1.61$ & $0.93 \pm 1.11$ & $<\mathbf{0 . 0 0 1}$ \\
\hline 2 hours & $2.53 \pm 1.36$ & $1.3 \pm 1.44$ & $1.3 \pm 1.18$ & $<\mathbf{0 . 0 0 1}$ \\
\hline 3 hours & $3.53 \pm 1.14$ & $1.77 \pm 1.55$ & $1.2 \pm 1.16$ & $<\mathbf{0 . 0 0 1}$ \\
\hline 4 hours & $3.6 \pm 1.19$ & $2.8 \pm 1.45$ & $1.87 \pm 1.1$ & $<\mathbf{0 . 0 0 1}$ \\
\hline 6 hours & $4.23 \pm 1.72$ & $3.67 \pm 0.76$ & $2.3 \pm 1.15$ & $\mathbf{0 . 0 1}$ \\
\hline 8 hours & $3.27 \pm 2.26$ & $3.4 \pm 1.23$ & $2.53 \pm 1.04$ & $<\mathbf{0 . 0 0 1}$ \\
\hline 12 hours & $2.78 \pm 1.78$ & $4.4 \pm 2.34$ & $1.87 \pm 1.25$ & $<\mathbf{0 . 0 0 1}$ \\
\hline 24 hours & $2.13 \pm 1.7$ & $3.37 \pm 1.19$ & $1.73 \pm 1.2$ & \\
\hline
\end{tabular}

Table-4: Comparison of Post-Operative Sedation Score at various time intervals among the study groups.

\begin{tabular}{|c|c|c|c|c|}
\hline \multirow{2}{*}{$\begin{array}{c}\text { Post-operative } \\
\text { Sedation Score at }\end{array}$} & Group B & Group BF & Group BC & \multirow{2}{*}{ P value } \\
\cline { 2 - 4 } & Mean \pm SD & Mean \pm SD & Mean \pm SD & 0.9479 \\
\hline 15 minutes & $2.3 \pm 0.47$ & $2.27 \pm 0.45$ & $2.3 \pm 0.47$ & 0.4327 \\
\hline 30 minutes & $2.03 \pm 0.18$ & $2.1 \pm 0.31$ & $2.03 \pm 0.18$ & $\mathbf{0 . 0 2 2 1}$ \\
\hline 45 minutes & $2 \pm 0.26$ & $2.23 \pm 0.43$ & $2.27 \pm 0.45$ & $\mathbf{0 . 0 4 9 3}$ \\
\hline 60 minutes & $2.1 \pm 0.55$ & $2.43 \pm 0.57$ & $2.5 \pm 0.51$ & $\mathbf{0 . 0 0 8 5}$ \\
\hline 2 hours & $2.03 \pm 0.49$ & $2.43 \pm 0.63$ & $2.4 \pm 0.5$ & $<\mathbf{0 . 0 0 1}$ \\
\hline 3 hours & $1.57 \pm 0.5$ & $2.33 \pm 0.61$ & $2.47 \pm 0.51$ & $<\mathbf{0 . 0 0 1}$ \\
\hline 4 hours & $1.42 \pm 0.54$ & $2.03 \pm 0.56$ & $2.2 \pm 0.41$ & $<\mathbf{0 . 0 0 1}$ \\
\hline 6 hours & $1.33 \pm 0.48$ & $1.63 \pm 0.49$ & $2.1 \pm 0.48$ & $<\mathbf{0 . 0 0 1}$ \\
\hline 8 hours & $1.21 \pm 0.28$ & $1.47 \pm 0.21$ & $1.83 \pm 0.33$ & $<\mathbf{0 . 0 0 1}$ \\
\hline 12 hours & $1.33 \pm 0.33$ & $1.37 \pm 0.76$ & $1.67 \pm 0.25$ & $<\mathbf{0 . 0 0 1}$ \\
\hline 24 hours & $1.22 \pm 0.35$ & $1.33 \pm 0.76$ & $1.57 \pm 0.51$ & \\
\hline
\end{tabular}

The percentage change in the heart rate was comparable across the study groups at various time intervals was comparable across the study groups, with a minor differences. (Figure 1)

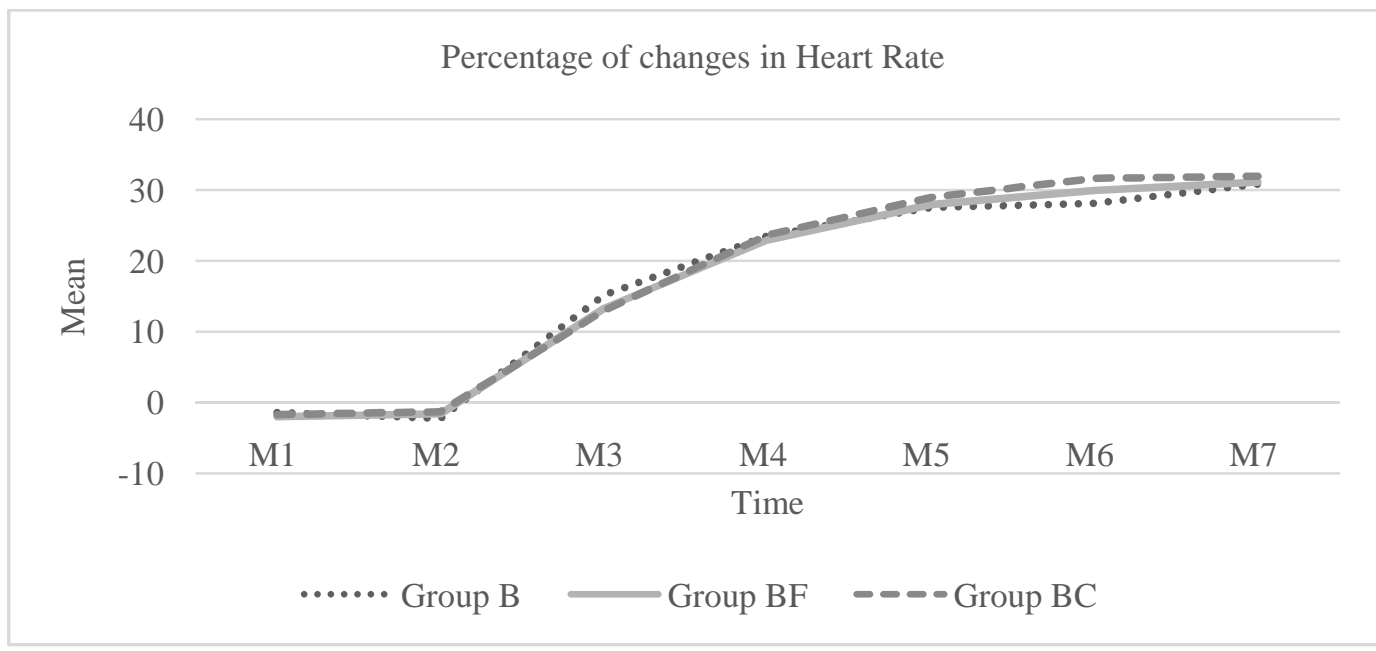

Figure-1: Trend diagram, comparing the percentage of changes in Heart Rates at various time intervals. 


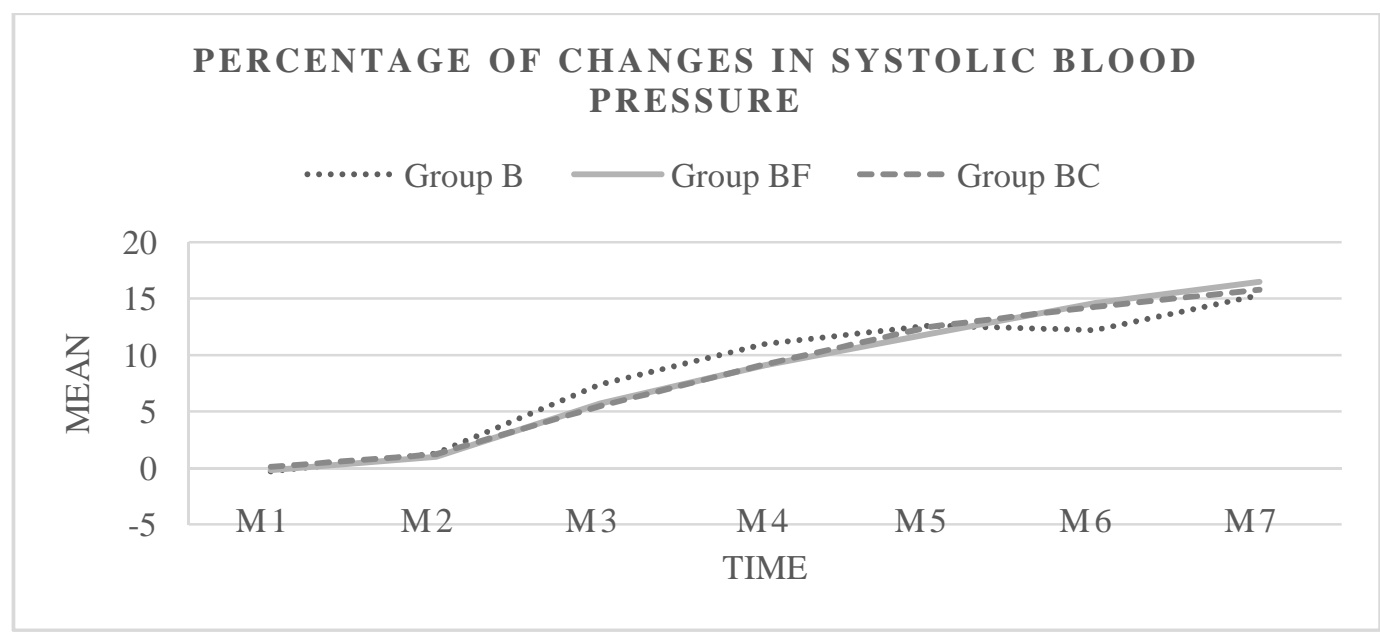

Figure-2: Trend diagram, comparing the percentage of changes Systolic Blood Pressure at various time intervals

The percentage change in the systolic blood pressure was comparable across the study groups at various time intervals was comparable across the study groups, with minor differences. (Figure 2)

\section{Discussion}

Though Sevoflurane is favored inhalational agent for inducing anesthesia in pediatric patients, it is associated with non-purposeful restlessness and agitated behavior usually termed as emergence agitation. However, the exact basis behind such an alteration is unknown and unrelieved pain remains one of the suggested causes [13]. For an effective postoperative pain management and to prevent emergence agitation, the chosen method has been a caudal block with a local anesthetic with or without adjuvants (fentanyl, clonidine) especially for infra umbilical surgeries. A single shot of caudal block provides effective postoperative analgesia and the duration of the block can be prolonged by using an adjuvant like opioids (fentanyl) [14] and more recently $\alpha^{2}$-agonist (clonidine) [15].

The findings of the study showed a statistically significant difference in the duration of postoperative analgesia and sedation among the three groups. This was in line with the double blind study by Akin et al., [16] in 60 children aged 2-8 years undergoing inguinal hernia repair, with one group of 20 received $0.25 \%$ levobupivacaine alone while two other groups were given additionally 2 micrograms per kg body weight of clonidine with or without $5 \mathrm{ml}$ saline found that caudal clonidine prolonged the duration of analgesia induced by levobupivacaine without significant side effects. Similarly a double-blind study by Ahuja S et al., [17] among 60 Indian children with three groups of $0.25 \%$ bupivacaine alone (group I), additionally with 1 microgram $/ \mathrm{kg}$ fentanyl (group II), 3 micro gram $/ \mathrm{kg}$ clonidine (group III) concluded that caudal clonidine prolonged analgesia and decreased emergence agitation as compared to bupivacaine alone or fentanyl.

Not only bupivacaine, even Ropivacaine has been shown to produce prolonged analgesia when combined with clonidine or fentanyl in epidural anesthesia without affecting the pharmacodynamics profile of the drugs and with significantly fewer side effects $[18,19]$.

Though fentanyl and clonidine do enhance the analgesic duration of bupivacaine, clonidine, in particular, is shown to have lesser side effects like reduced postoperative nausea and better patient satisfaction [11, $14,20,21]$.

\section{Conclusions}

To conclude the addition of clonidine $1 \mu \mathrm{g} / \mathrm{kg}$ to $0.25 \%$ bupivacaine administered as $1 \mathrm{ml} / \mathrm{kg}$ prolonged the duration of postoperative analgesia in children undergoing sub umbilical surgeries after a single shot caudal injection without any significant side effects when compared to bupivacaine $0.25 \%$ alone or its combination with fentanyl $1 \mu \mathrm{g} / \mathrm{kg}$.

\section{Limitations}

1. As the investigator blinding was not possible, the possibility of interviewer bias could not be eliminated completely 
2. Even though good baseline was achieved among the study groups, in terms of potential confounders, the magnitude of residual confounding could not be assessed by regression analysis, considering the smaller sample size.

3. Since multitude of surgeries was involved, the role of type of diseases and type of surgery performed as confounders also could not be evaluated

Recommendations: Further large-scale studies preferably conducted on subjects undergoing, similar surgical procedure may provide us more valid comparisons

\section{Funding: Nil, Conflict of interest: None Permission of IRB: Yes}

\section{References}

1. Verghese ST, Hannallah RS. Acute pain management in children. J Pain Res. 2010 Jul 15;3:105-23.

2. Lak M, Araghizadeh H, Shayeghi S, Khatibi B. Addition of clonidine in caudal anesthesia in children increases duration of post-operative analgesia. Trauma monthly.2012;16(4):170-4,10.5812/kowsar.22517464. 3393.

3. Russell P, von Ungern-Sternberg BS, Schug SA. Perioperative analgesia in pediatric surgery. Curr Opin Anaesthesiol. 2013 Aug; 26(4):420-7. doi: 10.1097/ ACO. 0b013e 3283625cc8.

4. Bösenberg A. Pediatric regional anesthesia update. Paediatr Anaesth. 2004 May;14(5):398-402.

5. Kraemer FW, Rose JB. Pharmacologic management of acute pediatric pain. Anesthesiol Clin. 2009 Jun;27 (2): 241-68. doi: 10.1016/j.anclin.2009.07.002.

6. Lloyd-Thomas AR. Pain management in paediatric patients. Br J Anaesth. 1990 Jan;64(1):85-104.

7. Khalil SN, Hanna E, Farag A, Govindaraj R, Vije H, Kee S, Chuang AZ. Presurgical caudal block attenuates stress response in children. Middle East J Anaesthesiol. 2005 Jun;18(2):391-400.

8. Motoyama EK DP, Cohn EL, Smith RM. Smith's anesthesia for infants and children. 7 ed. Mosby, An I Brint of Elsevier searc; 2005.
9. De Negri P IG, Visconti C, De Vivo P. How to prolong post-operative analgesia after caudal anaesthesia with ropivacaine in children: S-ketamine versus clonidine. Paediatr Anaesth 2001;11(6):679-83.

10. Meyer C CR. One hundred times the intended dose of caudal clonidine in three pediatric patients. Paediatr Anaesth. 2008;18(9):888-90.

11. Wheeler M PA, Suresh S, Roth AG, Birmingham $\mathrm{PK}, \mathrm{He}$ - ner CL, et al. . The addition of clonidine 2 microg.kg-1 does not enhance the postoperative analgesia of a caudal block using $0.125 \%$ bupivacaine and epinephrine 1:200,000 in children: a prospective, double-blind, randomized study. Paediatr Anaesth. 2005; 15(6):476-83.

12. Desai DJ SV, Gupta KK. . Comparative study of two different doses of fentanyl with $0.25 \%$ bupivacaine through caudal route for paediatric anaesthesia and postoperative analgesia. J Anaesth Clin Pharmacol $2008 ; 24: 31-4$.

13. El-Hennawy AM, Abd-Elwahab AM, AbdElmaksoud AM, El-Ozairy HS, Boulis SR. Addition of clonidine or dexmedetomidine to bupivacaine prolongs caudal analgesia in children. Br J Anaesth. 2009 Aug; 103 (2):268-74. doi: 10.1093/bja/aep159. Epub 2009 Jun 18 .

14. Desai DJ SV, Gupta KK. . Comparative study of two different doses of fentanyl with $0.25 \%$ bupivacaine through caudal route for paediatric anaesthesia and postoperative analgesia. J Anaesth Clin Pharmacol. 2008; 24:31-4.

15. Bock M, Kunz P, Schreckenberger R, Graf BM, Martin E, Motsch J. Comparison of caudal and intravenous clonidine in the prevention of agitation after sevoflurane in children. Br J Anaesth. 2002 Jun;88 (6):790-6.

16. Akin A, Ocalan S, Esmaoglu A, Boyaci A. The effects of caudal or intravenous clonidine on postoperative analgesia produced by caudal levobupivacaine in children. Paediatric anaesthesia. 2010; 20 (4):350-5,10.1111/j.1460-9592.2010.03259.x.

17. Ahuja S, Aggarwal M, Joshi N, Chaudhry S, Madhu SV. Efficacy of Caudal Clonidine and Fentanyl on Analgesia, Neuroendocrine Stress Response and 
Emergence Agitation in Children Undergoing Lower Abdominal Surgeries Under General Anaesthesia with Sevoflurane. Journal of clinical and diagnostic research: JCDR. 2015; 9 (9): Uc01-5, 10. 7860/jcdr/ 2015/ 12993. 6423.

18. Bajwa SJ, Bajwa SK, Kaur J, Singh A, Bakshi G, Singh K, et al. Admixture of clonidine and fentanyl to ropivacaine in epidural anesthesia for lower abdominal surgery. Anesthesia, essays and researches. 2010;4(1): 9-14, 10.4103/0259-1162.69299.

19. Sengupta S, Mukherji S, Sheet J, Mandal A, Swaika $S$. Caudal-epidural bupivacaine versus ropivacaine with fentanyl for paediatric postoperative analgesia.
Anesthesia, essays and researches. 2015; 9(2): 20812,10. 4103/0259-1162.154541.

20. Topcu I, Luleci N, Tekin S, Kefi A, Erincler T. [Effectiveness of clonidine and fentanyl addition to bupivacaine in postoperative patient controlled epidural analgesia]. Anasthesiologie, Intensivmedizin, Notfallmedizin, Schmerztherapie : AINS. 2005;40(9): 521-5, 10.1055/s-2005-870397.

21. Sharan R, Verma R, Dhawan A, Kumar J. Comparison of clonidine and fentanyl as adjuvant to ropivacaine in spinal anesthesia in lower abdominal surgeries. Anesthesia, essays and researches. 2016; 10 (3): 526-31,10.4103/0259-1162.180781.

\section{How to cite this article?}

Malarvizhi T, Kannan, Rajesh, Poornima. A comparative study of Fentanyl and Clonidine as additives to plain Bupivacaine in caudal anaesthesia in children. Int J Med Res Rev 2017;5(03):324-330 doi:10.17511/ijmrr. 2017.i03.18. 